\title{
Análise da precipitação pluvial e temperatura do ar de Olho D'Água do Casado, Delmiro Gouveia e Piranhas, Alagoas
}

\author{
Analysis of rainfall and air temperature of Olho D'Água do Casado, Delmiro Gouveia and \\ Piranhas, Alagoas
}

\author{
SANTOS $^{1}$, G. R.; SANTOS ${ }^{1}$, É. M. C.; $\operatorname{LIRA}^{1}$, E. S.; GOMES ${ }^{1}$, D. L.; $\operatorname{SOUZA}^{2}$, M. A.; \\ ARAUJO $^{3}$, K. D. \\ geovaniaricardo@hotmail.com
}

\begin{abstract}
Resumo
Na região Semiárida brasileira a precipitação pluvial caracteriza-se por apresentar alta variabilidade de distribuição, geralmente concentrada no período de três a quatro meses do ano, em contraposição aos elementos irradiação solar, insolação e temperaturas do ar e do solo, apresentam pouca variação. Diante deste contexto, objetivou-se analisar os elementos climáticos precipitação pluvial e temperatura do ar no período de 1911 a 1990 para os municípios de Olho D'Água do Casado, Delmiro Gouveia e Piranhas, Alagoas. Foram utilizados valores médios de dados do período (1911 a 1990) referentes aos elementos climáticos precipitação pluvial (mm) e temperatura do ar $\left({ }^{\circ} \mathrm{C}\right)$, do banco de dados gerados e/ou coletados pela Unidade Acadêmica de Ciências Atmosféricas (UACA). Foi aplicado o Índice de Aridez de De Martonne e elaborado o Diagrama Ombrotérmico para representar o período seco da região. A partir das informações levantadas é possível constatar que os municípios pesquisados apresentam dois períodos bem definidos, seco (de estiagem) e chuvoso com alta variabilidade da precipitação pluvial entre os meses avaliados (1911-1990); o período chuvoso abrange maior número de meses em Olho D’Água do Casado quando comparado a Delmiro Gouveia e Piranhas; o período seco se estabelece com maior número de meses nos três municípios analisados.
\end{abstract}

Palavras-chave: Clima. Semiárido. Índice de aridez.

\begin{abstract}
In the semi-arid region of Brazil, rainfall is characterized by high variability of distribution, generally concentrated in the three to four months of the year, as opposed to solar radiation, insolation, and air and soil temperatures. In this context, the present study aimed to analyze the climatic elements rainfall and air temperature in the period from 1911 to 1990 at Olho D'Agua do Casado, Delmiro Gouveia and Piranhas, Alagoas. Mean values were used for the period (1911 to 1990) of rainfall (mm) and air temperature $\left({ }^{\circ} \mathrm{C}\right.$ ) data from the database generated and/or collected by the Atmospheric Sciences Academic Unit (UACA). The De Martonne Aridity Index and the Ombrothermal Diagram were used to represent the dry period of the region. Based on the information collected, it is possible to observe that the cities surveyed have two well-defined periods, dry (drought) and rainy seasons with high variability of rainfall between evaluated months (1911-1990); The rainy season covers higher number of months in Olho D'Água do Casado when compared to Delmiro Gouveia and Piranhas; The dry period is established with the highest number of months in the three municipalities analyzed.
\end{abstract}

Keywords: Weather. Semi-arid. Dryness index.

\section{INTRODUÇÃO}

O clima é o conjunto de tendências, de elementos do ambiente atmosférico composto pela série de estados da atmosfera em um determinado lugar em uma sucessão de tempo. As diversas 
situações atmosféricas, como os processos biológicos e físicos, são tidas como essenciais à configuração do clima (BARROS e ZAVATTINI, 2009).

Para Monteiro (1999) a concepção de clima é sintética. O clima se manifesta através da percepção dos regimes, ou seja, a variação anual. Se os regimes são observações feitas separadamente para os diferentes elementos (pressão, temperatura, umidade, precipitação, vento, dentre outros) a noção sintética de clima advém do ritmo de sucessão dos tipos de tempo, configurados em cadeias nas sucessões mais habituais. Nesse sentido, o entendimento de seus elementos torna-se possível, de modo particular estudando minuciosamente cada uma de suas partes, visto que o estudo do clima de um modo global torna-se complexo, uma vez que para Demillo (1998) o clima é uma força que jamais se pode compreender totalmente.

De acordo com Andrade et al. (2008) e Lopes et al. (2009) o Nordeste brasileiro é caracterizado por apresentar acentuada variabilidade interanual em relação à precipitação e à disponibilidade dos recursos hídricos, com anos extremamente secos e outros chuvosos. De acordo com Ayoade (2007) essa alta variabilidade implica que há amplas flutuações em torno do valor médio de ocorrência e quanto maior for o período avaliado mais precisa será sua concepção.

De acordo com Galego (1970) as médias climatológicas além de serem necessárias para a elaboração de classificação climática sazonal e planetária, também são importantes para o estudo de fenômenos atmosféricos isolados, como a temperatura, pluviosidade, dentre outros, o que permite precisar as diferentes épocas em que se registra a estação seca (ou úmida) de uma ampla região e ainda a caracterização das anomalias climáticas, sendo necessária a aplicação do método geográfico da climatologia tradicional ou clássica. Ainda de acordo com a autora, quando num longo período de observações encontram-se determinados anos em que as características se afastam da média, registram-se anomalias que podem referir-se a elementos isolados e essas são identificadas a partir das normais climatológicas, que segundo a Organização Meteorológica Mundial referem-se às médias de períodos relativamente uniformes de pelo menos três períodos consecutivos de 10 anos (SUDENE, 1963). É com base nas normais climatológicas que se determina a média climática de uma determinada área ou região.

No entanto, quando se pretende identificar o comportamento do clima de determinada área em um pequeno intervalo de tempo, aplicando-se o método da climatologia dinâmica, o resultado obtido a partir das médias apresentará valores distantes da realidade, os valores expressam tendências a mascaramento, pois não possibilitam a leitura da realidade diária do fenômeno, uma vez que escondem as variações de pequenos períodos. Para Nimer (1972) as normais climatológicas, pelo seu caráter estático, mascaram diversos tipos de tempo que fazem parte do clima, diluindo-os nas médias. 
De acordo com Ayoade (2007) na região Semiárida a precipitação pluvial é variável em sua incidência/regularidade e apresentam características como duração, frequência, quantidade e intensidade (quantidade de precipitação dividida pela duração da tempestade em horas e minutos, onde esta varia com o intervalo de tempo usado), isso ocorre porque o índice de variabilidade é a medida do grau de probabilidade da quantidade média que se repete a cada ano, estação, mês, dependendo do período analisado. Deste modo, a análise efetiva temporal e sazonal dos elementos climáticos, permitem ajudar os gestores a planejar as atividades de uma localidade, de acordo com a sua vocação, podendo reduzir os riscos e aperfeiçoar os benefícios socioeconômicos de uma região.

De modo geral ainda há dificuldade na obtenção de dados dos elementos climáticos para todo o território nacional. No caso de alguns Estados brasileiros além da ausência de estações meteorológicas também há problemas de articulação entre as mesmas, são vários órgãos coletando dados, mas sem banco de informações em comum para acesso da sociedade (SPECIAN e ANDRADE, 2011).

Diante do exposto buscou-se através do banco de dados da Unidade Acadêmica de Ciências Atmosféricas, da Universidade Federal de Campina Grande, que dispõe de valores climatológicos de temperatura do ar e precipitação média mensal, analisar a variabilidade dos elementos climáticos temperatura do ar e precipitação pluvial no período de 1911 a 1990 para os municípios de Olho D’Água do Casado, Delmiro Gouveia e Piranhas, no Estado de Alagoas, período em que a estação meteorológica esteve em operação.

\section{METODOLOGIA}

\subsection{Caracterização dos municípios estudados}

Os municípios analisados são Olho D’Água do Casado (9 $31^{\circ}$ ' S e 3751' W; altitude de 209 m), Delmiro Gouveia $\left(9^{\circ} 23^{\prime} \mathrm{S}\right.$ e $37^{\circ} 59^{\prime} \mathrm{W}$; altitude de $\left.256 \mathrm{~m}\right)$ e Piranhas $\left(9^{\circ} 37^{\prime} \mathrm{S}\right.$ e $37^{\circ} 46^{\prime} \mathrm{W}$; altitude de 110 m) (DCA, 2013) (Figura 1) e Estão localizados na Mesorregião do Sertão e Microrregião Alagoana do Sertão do São Francisco (SEPLANDE, 2013). 


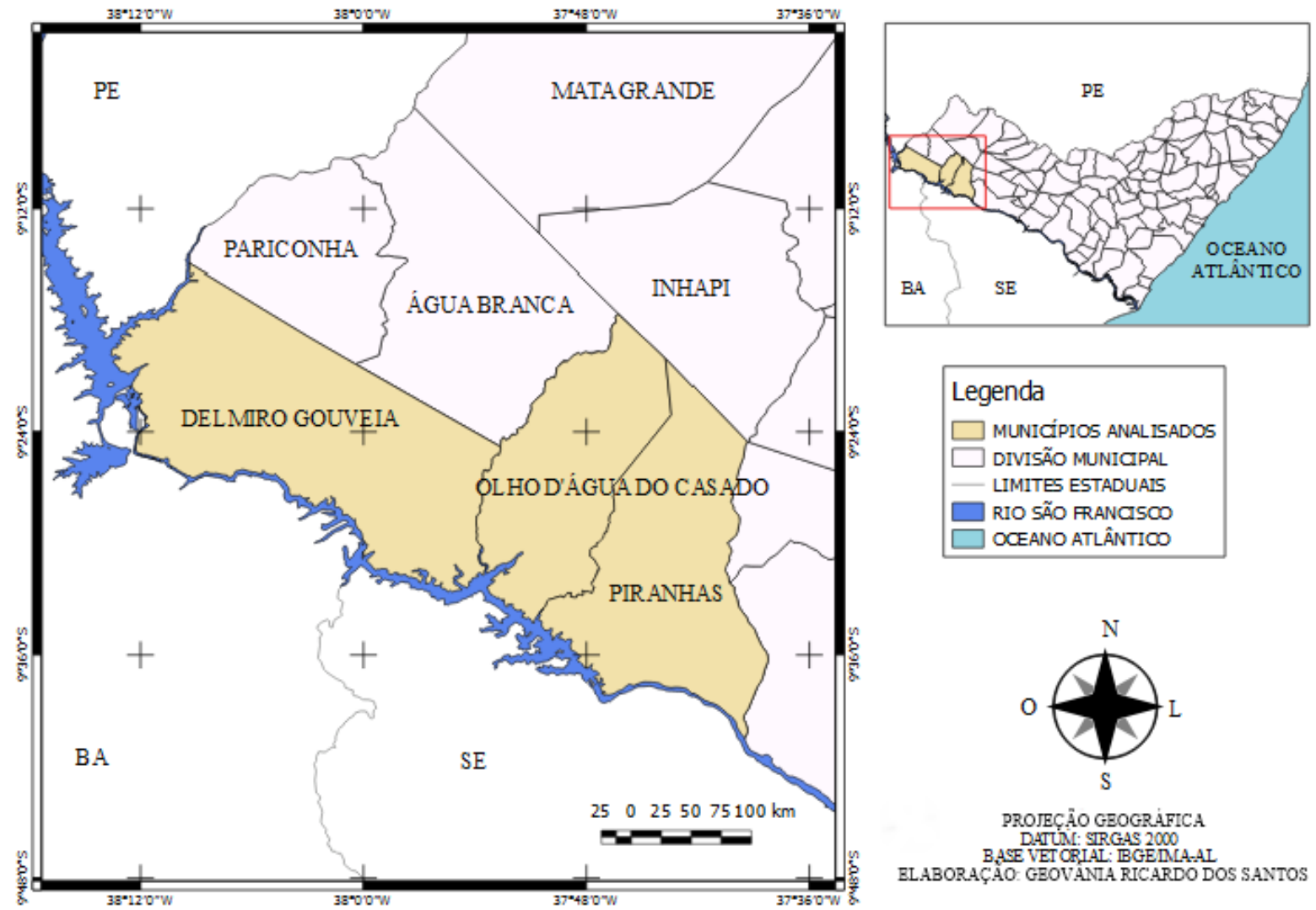

Figura 1. Localização dos municípios de Olho D’Água do Casado, Delmiro Gouveia e Piranhas, Semiárido alagoano. Elaboração: Geovânia Ricardo dos Santos.

A geomorfologia dos municípios de Olho D’Água do Casado, Delmiro Gouveia e Piranhas têm parte de sua área inserida na unidade geoambiental da Depressão Sertaneja, paisagem típica do Semiárido Nordestino. Ocorrem superfícies de pediplanação, relevo predominantemente suaveondulado, cortadas por vales estreitos e vertentes dissecadas (LIMA, 1977).

Os solos que ocorrem predominantemente nas regiões são de dois tipos: os Neossolos Líticos e os Neossolos Flúvicos (EMBRAPA, 2014).

O clima da área é do tipo BSh - Tropical semiárido, segundo a classificação de Köppen (LIMA, 1977). A precipitação média de Olho D’Água do Casado é de 545,6 mm/ano, enquanto Delmiro Gouveia e Piranhas possuem um valor médio de 512,1 e 492,2 mm/ano, respectivamente (Tabela 1). A época chuvosa em Piranhas tem início em março e vai até julho e nos dois outros municípios ocorre de fevereiro a julho. A temperatura média do ar anual de Olho D’Água do Casado corresponde a $25,6^{\circ} \mathrm{C}$, enquanto Delmiro Gouveia e Piranhas apresentam um valor médio de 25,5 e $26,6^{\circ} \mathrm{C}$, respectivamente. A média da umidade relativa do ar é de $74,4 \%$ para os três municípios (DCA, 2013) (Tabela 1). 
Tabela 1. Precipitação pluvial (mm/ano), Temperatura do ar $\left({ }^{\circ} \mathrm{C}\right)$ e Umidade relativa do ar $(\%)$, para os municípios Alagoanos de Olho D’Água do Casado, Delmiro Gouveia e Piranhas. Fonte: DCA, 2013

\begin{tabular}{|c|c|c|c|}
\hline \multirow[t]{2}{*}{ Elementos climáticos } & \multicolumn{3}{|c|}{ Municípios } \\
\hline & Olho D’Água do Casado & Delmiro Gouveia & Piranhas \\
\hline Precipitação pluvial (mm/ano) & 545,6 & 512,1 & 492,2 \\
\hline Temperatura do ar $\left({ }^{\circ} \mathrm{C}\right)$ & 25,6 & 25,5 & 26,6 \\
\hline Umidade relativa do ar $(\%)$ & & $-74,4-$ & \\
\hline
\end{tabular}

A vegetação predominante é a Caatinga Hipoxerófila com trechos de Floresta Caducifólia, que perdem suas folhas durante a estação seca, compreendem variadas associações entre mata seca e campos, caracterizadas por formações xerófilas, lenhosas, decíduas, em geral espinhosas, com presença de plantas suculentas e estrato herbáceo estacional, além de uma ampla variação florística (SANTANA e SOUTO et al., 2006). Diversas espécies podem ser encontradas, como: cactáceas, juazeiro (Ziziphus joazeiro Mart.), pereiro (Aspidosperma pyrifolium Mart.), angico (Parapiptadenia zehntneri (Harms) M. P. Lima e H. C. Lima), dentre outros (ANDRADE et al., 2006).

\subsection{Descrição da metodologia}

Realizou-se inicialmente uma análise da temperatura do ar e precipitação pluvial dos municípios de Olho D’Água do Casado, Delmiro Gouveia e Piranhas, a partir dos dados médios e do diagrama ombrotérmico da região.

Os dados médios do período (1911 a 1990) referentes aos elementos climáticos precipitação pluvial $(\mathrm{mm})$ e temperatura do ar $\left({ }^{\circ} \mathrm{C}\right)$ foram obtidos do banco de dados do Departamento de Ciências Atmosféricas (DCA, 2013), atualmente denominada Unidade Acadêmica de Ciências Atmosféricas (UACA), por meio de estação meteorológica instalada em cada localidade, durante o período analisado.

A partir desses dados foram aplicados para os três locais pesquisados o Índice de Aridez de De Martonne (i), estimado a partir da aplicação do modelo:

$$
\mathrm{i}=12 \cdot \mathrm{p} /(\mathrm{t}+10)
$$

Em que:

$\mathrm{p}=$ precipitação pluvial mensal $(\mathrm{mm})$;

$\mathrm{t}=$ temperatura média mensal $\left({ }^{\circ} \mathrm{C}\right)$.

O índice de aridez varia de 0-5 (Desértico), 6-10 (Semidesértico), 11-20 (Estepes e países secos mediterrâneos), 21-30 (Região de cultivo de plantas de sequeiro e cereais) (DAJOZ, 1983). 
Foram confeccionados os diagramas ombrotérmicos das três áreas estudadas, tendo sido necessário traçar um gráfico em que foram inseridos nas abscissas os meses e nas ordenadas às temperaturas e as precipitações (DAJOZ, 1983).

\section{RESULTADOS E DISCUSSÃO}

Analisando-se o diagrama ombrotérmico elaborado a partir dos dados médios do período (1911-1990) para as áreas estudadas, observou-se que há duas estações bem definidas, uma seca (estiagem) e outra chuvosa. Nos três municípios estudados verificou-se que a estiagem inicia-se no final do mês julho e prolonga-se até fevereiro, sendo que em Piranhas a estação seca se estende até a metade de março. Em relação ao período chuvoso observou-se que com exceção de Piranhas, cujo período chuvoso começa em março, nos demais municípios a época de chuva ocorre de fevereiro a julho (Figura 2).

De acordo com Pereira et al. (2012) o período chuvoso na mesorregião Semiárida de Alagoas se concentra no primeiro semestre do ano com maiores precipitações a partir do mês de março, como consequência da atuação da Zona de Convergência Intertropical (ZCIT), enquanto o período seco ocorre no segundo semestre do ano a partir do mês de outubro.

Para Marengo et al. (2011) a estação seca, em boa parte da porção Semiárida do Nordeste, ocorre entre os meses de agosto e outubro. Utilizando-se como critério para avaliar a vulnerabilidade climática da região o percentual de dias com déficit hídrico (relação entre o número de dias com déficit hídrico e o número total de dias), sugere-se que o Semiárido apresenta déficit hídrico em pelo menos 70\% do ano, pela estimativa do período 1970 a 1990 do DCA (2013).
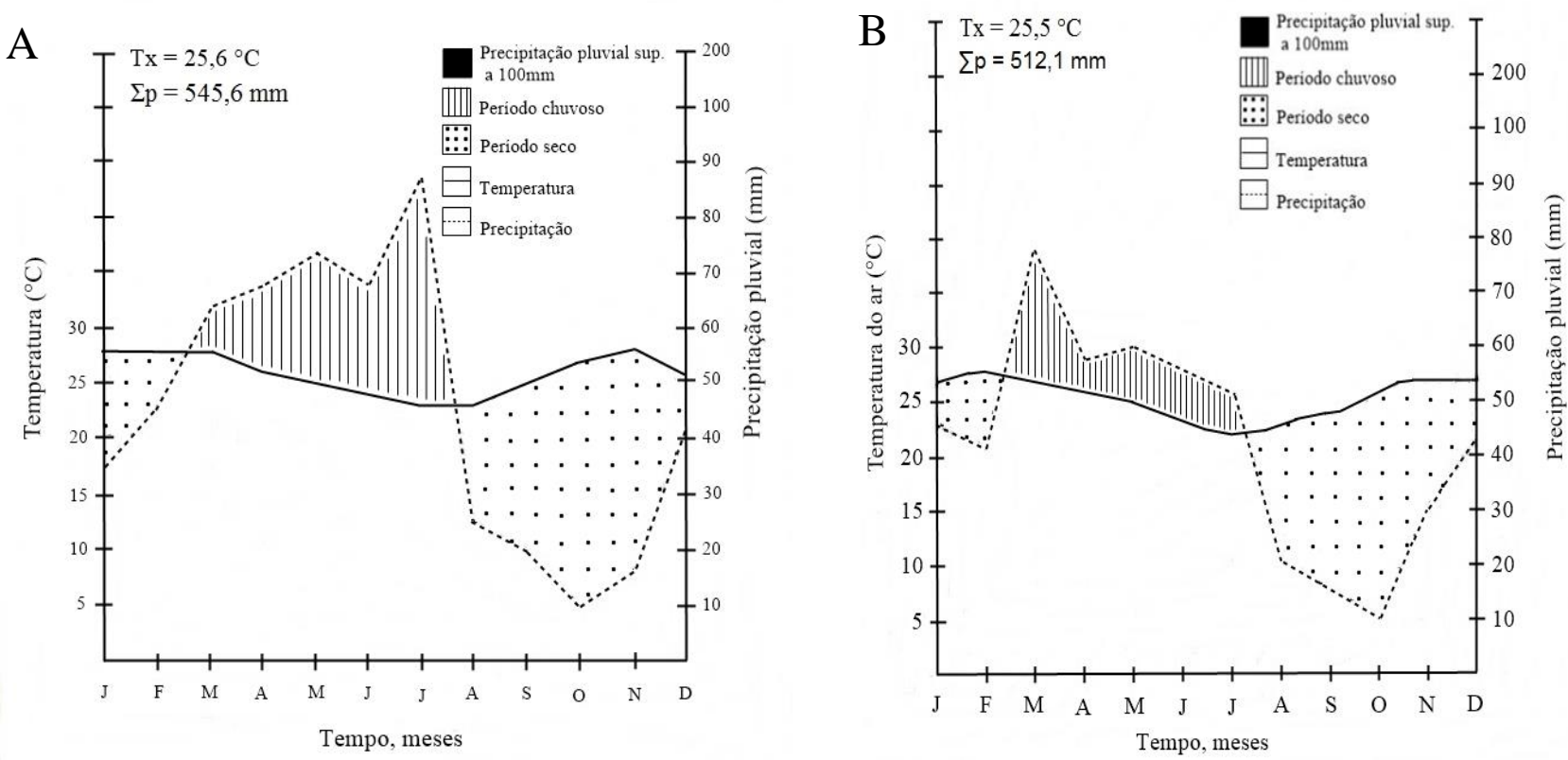


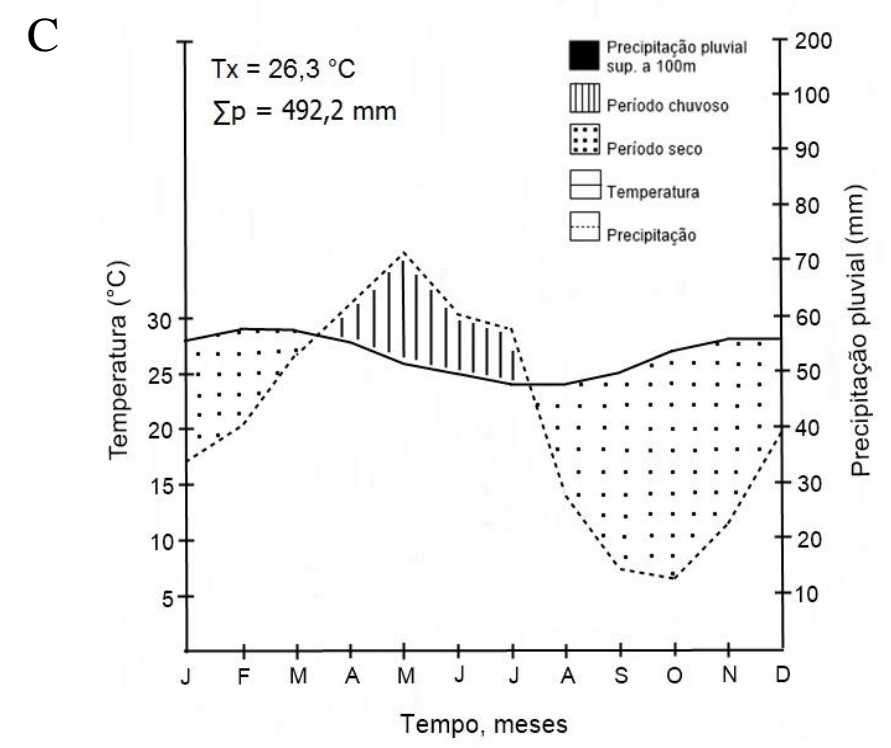

Figura 2. Diagrama ombrotérmico idealizado por Gaussen, onde a estação seca é representada em pontilhado e a secura se estabelece quando a pluviosidade mensal $\mathrm{P}$, expressa em $\mathrm{mm}$, é inferior ao dobro da temperatura média mensal T, em ${ }^{\circ} \mathrm{C}$, referente ao período de janeiro a dezembro 1911-1990 para os municípios Alagoanos de Olho D’Água do Casado (A), Delmiro Gouveia (B) e Piranhas (C). Organização: Os autores.

Com relação à temperatura do ar verificou-se que houve baixa variação entre as áreas, já que os valores médios apresentados foram 25,6, 25,5 e 26,5 ${ }^{\circ} \mathrm{C}$ para Olho D’Água do Casado (Figura 2A), Delmiro Gouveia (Figura 2B) e Piranhas (Figura 2C), respectivamente. Quanto à precipitação pluvial média anual, os valores apresentaram variabilidade com totais de 545,6 $\mathrm{mm}$ em Olho D’Água do Casado (Figura 2A), 512,1 mm em Delmiro Gouveia (Figura 2B) e em Piranhas foram registrados 492,2 $\mathrm{mm}$ (Figura 2C).

A combinação do aumento da temperatura do ar, redução das chuvas e da umidade atmosférica, fornece as ferramentas necessárias para gerar secas (Precipitação<Evapotranspiração), podendo, de fato, reduzir a umidade armazenada pelo solo ao longo do ano (MARENGO et al., 2011).

A partir da aplicação do Índice de Aridez de De Martonne, observou-se que em Olho D’Água do Casado, de agosto a fevereiro (período de estiagem) houve variação quanto à classificação climática, apresentando-se do tipo Seco (janeiro, fevereiro e dezembro), Semidesértico (agosto, setembro e dezembro) e Desértico em outubro, considerado o período mais crítico com um índice de 3,149, decorrente do baixo valor de precipitação pluvial (9,5 mm). Em relação ao período chuvoso observou-se que correspondeu aos meses de março a julho (Tabela 2). 
Tabela 2. Índice de aridez mensal pelo modelo de De Martonne para Olho D’Água do Casado, Alagoas, período de janeiro a dezembro $(1911$ - 1990). Organização: Os autores.

\begin{tabular}{c|c|c|c|c}
\hline Meses & Precipitação $(\mathrm{mm})$ & Temperatura $\left({ }^{\circ} \mathrm{C}\right)$ & I (Indice de Aridez) & Classificação \\
\hline $\mathrm{J}$ & 34,8 & 27,4 & 11,165 & Seco \\
\hline $\mathrm{F}$ & 46,0 & 27,6 & 14,680 & Seco \\
\hline $\mathrm{M}$ & 63,7 & 27,5 & 20,384 & Chuvoso \\
\hline $\mathrm{A}$ & 67,3 & 26,4 & 22,186 & Chuvoso \\
\hline $\mathrm{M}$ & 73,2 & 24,7 & 25,314 & Chuvoso \\
\hline $\mathrm{J}$ & 67,9 & 23,4 & 24,395 & Chuvoso \\
\hline $\mathrm{J}$ & 83,7 & 22,7 & 30,715 & Chuvoso \\
\hline $\mathrm{A}$ & 24,9 & 22,9 & 9,082 & Semidesértico \\
\hline $\mathrm{S}$ & 19,7 & 24,3 & 6,892 & Semidesértico \\
\hline $\mathrm{O}$ & 9,5 & 26,2 & 3,149 & Desértico \\
\hline $\mathrm{N}$ & 15,6 & 27,3 & 5,018 & Semidesértico \\
\hline $\mathrm{D}$ & 41,5 & 27,4 & 13,315 & Seco \\
\hline
\end{tabular}

Em Delmiro Gouveia, o período de estiagem, de acordo com o resultado da aplicação do Índice de Aridez de De Martonne, ocorreu de junho a fevereiro, sendo classificado como Semidesértico (agosto, setembro e novembro) e Desértico em outubro, quando também foi registrado o menor índice de aridez (3,290) e menor precipitação pluvial (9,9 mm). Nos meses de janeiro, fevereiro, abril, junho, julho e dezembro o tipo climático foi classificado como Seco. O período chuvoso foi constatado somente nos meses de março e maio (Tabela 3).

Tabela 3. Índice de aridez mensal pelo modelo de De Martonne para Delmiro Gouveia-AL, período de janeiro a dezembro (1911 - 1990). Organização: Os autores.

\begin{tabular}{c|c|c|c|c}
\hline Meses & Precipitação $(\mathrm{mm})$ & Temperatura $\left({ }^{\circ} \mathrm{C}\right)$ & $\mathrm{I}$ (Índice de Aridez) & Classificação \\
\hline $\mathrm{J}$ & 45,5 & 27,3 & 14,638 & Seco \\
\hline $\mathrm{F}$ & 42,4 & 27,5 & 13,568 & Seco \\
\hline $\mathrm{M}$ & 78,4 & 27,4 & 25,155 & Chuvoso \\
\hline $\mathrm{A}$ & 58,3 & 26,2 & 19,325 & Seco \\
\hline $\mathrm{M}$ & 60,2 & 24,5 & 20,939 & Chuvoso \\
\hline $\mathrm{J}$ & 55,0 & 23,1 & 19,939 & Seco \\
\hline $\mathrm{J}$ & 51,5 & 22,4 & 19,074 & Seco \\
\hline $\mathrm{A}$ & 21,4 & 22,7 & 7,853 & Semidesértico \\
\hline $\mathrm{S}$ & 15,5 & 24,2 & 5,438 & Semidesértico \\
\hline $\mathrm{O}$ & 9,9 & 26,1 & 3,290 & Desértico \\
\hline $\mathrm{N}$ & 29,7 & 27,3 & 9,554 & Semidesértico \\
\hline $\mathrm{D}$ & 43,3 & 27,3 & 13,930 & Seco \\
\hline
\end{tabular}

Já em Piranhas, de acordo com o índice aplicado, o período de estiagem foi registrado entre os meses de agosto a março, sendo classificado como Semidesértico (agosto e novembro), Desértico em setembro e outubro, este último apresentando o menor índice de aridez $(4,173)$ e menor 
precipitação pluvial (12,8 mm), Seco nos meses de janeiro, fevereiro, março e dezembro (Tabela 4). O período chuvoso foi constatado nos meses de abril a julho.

Tabela 4. Índice de aridez mensal pelo modelo de De Martonne para Piranhas-AL, período de janeiro a dezembro (1911 - 1990). Organização: Os autores.

\begin{tabular}{c|c|c|c|c}
\hline Meses & Precipitação $(\mathrm{mm})$ & Temperatura $\left({ }^{\circ} \mathrm{C}\right)$ & I (Índice de Aridez) & Classificação \\
\hline J & 34,3 & 28,0 & 10,831 & Seco \\
\hline F & 40,4 & 28,1 & 12,724 & Seco \\
\hline M & 53,3 & 28,2 & 16,743 & Seco \\
\hline A & 61,8 & 27,1 & 19,989 & Chuvoso \\
\hline M & 71,3 & 25,4 & 24,169 & Chuvoso \\
\hline J & 60,3 & 24,2 & 21,157 & Chuvoso \\
\hline J & 58,0 & 23,5 & 20,776 & Chuvoso \\
\hline A & 27,8 & 23,6 & 9,928 & Semidesértico \\
\hline S & 14,7 & 24,9 & 5,054 & Desértico \\
\hline O & 12,8 & 26,8 & 4,173 & Desértico \\
\hline N & 22,3 & 27,9 & 7,060 & Semidesértico \\
\hline D & 38,8 & 27,9 & 12,289 & Seco \\
\hline
\end{tabular}

Ao analisar os gráficos de precipitação pluvial e temperatura do ar, nos três municípios, também se verificou alta variabilidade que está expressa nas barras de desvio padrão das médias (Figura 3). Os volumes pluviométricos mais representativos para os três municípios estudados ocorreram entre o período de março a julho, oscilando entre 60 e $80 \mathrm{~mm}$ para Olho D'Água do Casado (A), entre 40 e $80 \mathrm{~mm}$ em Delmiro Gouveia (B) e de 40 a $80 \mathrm{~mm}$ em Piranhas. Foi constatado também que nesta época de maior ocorrência de precipitação pluvial os valores de temperatura apresentaram um decréscimo, em todos os municípios (Figura 3).

A

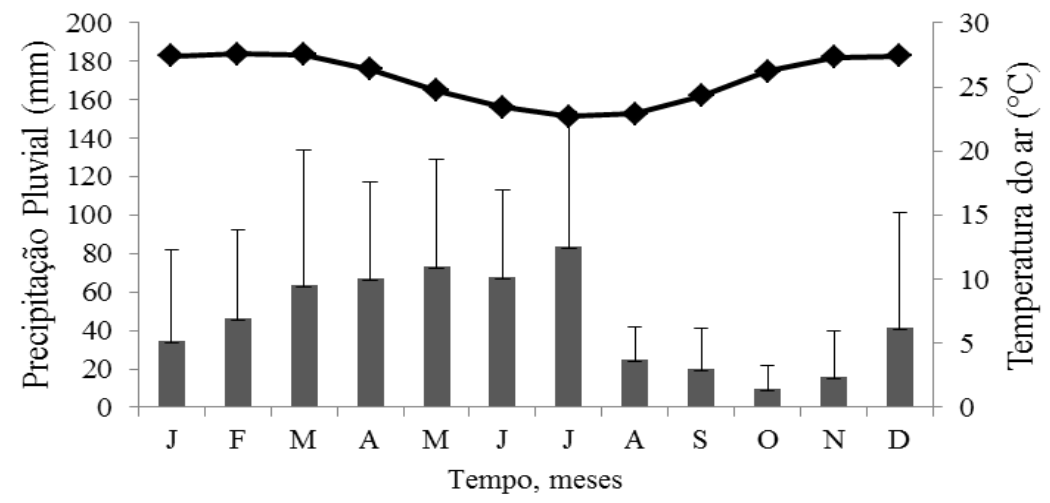

PRECIPITAÇÃO PLUVIAL $(\mathrm{mm}) \multimap$ TEMPERATURA DO AR $\left({ }^{\circ} \mathrm{C}\right)$ 
B

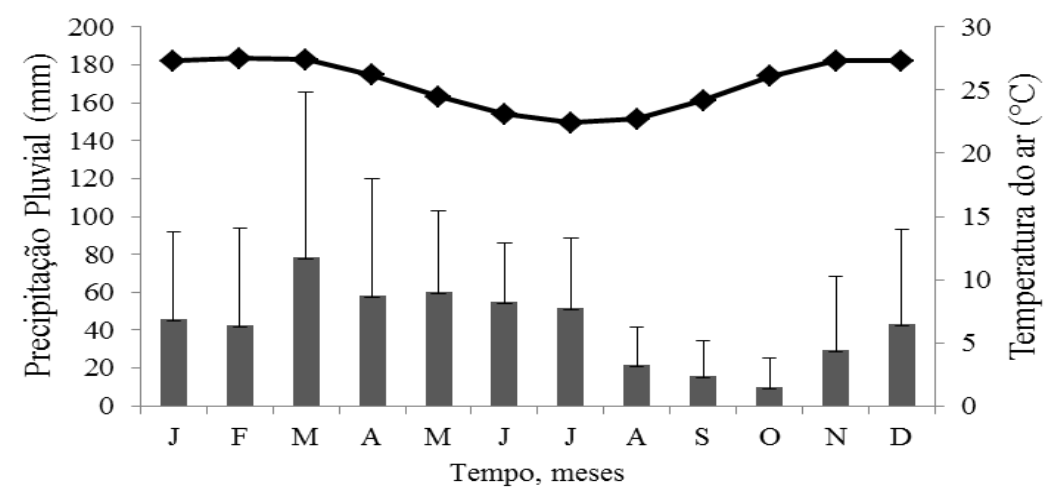

PRECIPITAÇÃO PLUVIAL $(\mathrm{mm}) \longrightarrow$ TEMPERATURA DO AR $\left({ }^{\circ} \mathrm{C}\right)$

$\mathrm{C}$

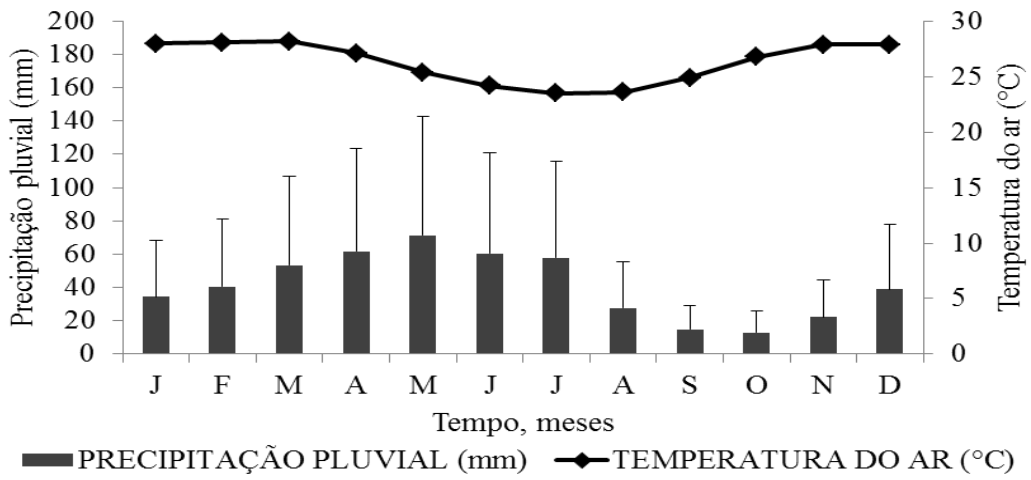

Figura 3: Precipitação pluvial (mm) e Temperatura do ar $\left({ }^{\circ} \mathrm{C}\right)$ para os municípios de Olho D’Água do Casado (A), Delmiro Gouveia (B) e Piranhas (C). Organização: Os autores.

Embora os locais pesquisados sejam geograficamente próximos há uma variação da precipitação pluvial entre as áreas pesquisadas. De acordo com Andrade et al. (2006) nas regiões Semiáridas há predominância de precipitações pluviais concentradas em poucos meses do ano e com alta variabilidade de distribuição. De acordo com Sampaio (1995) a irregularidade da precipitação pluvial é a característica principal da região Semiárida, apresentando um prolongado período seco, que se reflete na paisagem. O regime de precipitação é altamente variável entre os diferentes anos, como também, durante a estação de chuvas a cada ano.

Cabe mencionar que o Semiárido Nordestino também é vulnerável a enchentes e/ou chuvas intensas. De acordo com Marengo et al. (2011) entre os anos mais chuvosos na região, tem-se: 1964, 1967, 1974, 1985, 1986, 1988, 1989, 1994, 2004 e 2009, resultando nos vários episódios de chuvas intensas, na categoria forte (maior que $60 \mathrm{~mm} \mathrm{~h}^{-1}$ ), em 1985 e as fortes chuvas ocorridas em janeiro de 2004. No último caso, apenas neste mês choveu mais de $1.000 \mathrm{~mm}$. A média histórica varia entre 550 a $600 \mathrm{~mm}$ anuais. 
Molion (1983) ressalta que uma precipitação de $1 \mathrm{~mm}$, corresponde a uma chuva que despeja sobre a superfície atingida uma lâmina de água de $1 \mathrm{~mm}$. Isso equivale a 1 litro de água por metro quadrado $\left(1 \mathrm{~L} / \mathrm{m}^{2}\right)$. Uma chuva forte, que perdure durante seis horas, pode atingir $100 \mathrm{~mm}, \mathrm{o}$ que significa $100 \mathrm{~L} / \mathrm{m}^{2}$.

De acordo com Marengo et al. (2011) o mais importante sistema sinóptico de chuvas na região é a zona de convergência intertropical (ZCIT), que representa o eixo do cavado equatorial e suas variações em posição e intensidade que estão diretamente relacionadas às alterações nas posições e intensidades das altas subtropicais do Atlântico Norte e Sul. A ZCIT apresenta, no Atlântico, a convergência dos ventos alísios do Norte e Sul, com movimentos ascendentes, baixas pressões, nebulosidades e chuvas abundantes e segue, preferencialmente, as regiões em que a temperatura da superfície do mar (TSM) é mais elevada.

\section{CONSIDERAÇÕES FINAIS}

Os municípios pesquisados apresentam dois períodos bem definidos, seco (de estiagem) e chuvoso com alta variabilidade da precipitação pluvial entre os meses avaliados (1911-1990).

Embora os municípios sejam geograficamente próximos, o período chuvoso abrange maior número de meses em Olho D’Água do Casado quando comparado a Delmiro Gouveia e Piranhas.

O período seco se estabelece com maior número de meses nos três municípios analisados.

\section{REFERÊNCIAS}

ANDRADE, R. L. de et al. Deposição de serrapilheira em área de caatinga na RPPN "Fazenda Tamanduá", Santa Terezinha-PB. Revista Caatinga, v. 21, n. 2. Mossoró: 2008.

ANDRADE, A. P. de et al. Produção animal no bioma caatinga: paradigmas dos pulsos-reserva. Revista Brasileira de Zootecnia, v. 35, 2006. (Suplemento especial).

AYOADE, J. O. Introdução à climatologia para os trópicos. 12 ed. São Paulo: Bertrand Brasil, 2007. $332 \mathrm{p}$.

BARROS, J. R.; ZAVATTINI, J. A. Bases conceituais em climatologia geográfica. Revista de Geografia da UFC, v. 8, n. 16, Ceará: 2009.

DAJOZ, R. Ecologia geral. 1 ed. Petrópolis: Vozes, 1983. 472 p.

DCA-DEPARTAMENTO DE CIÊNCIAS ATMOSFÉRICAS. Dados climatológicos do Estado de Alagoas: Campina Grande: UFCG-CTRN, 2013. Disponível em: 〈www.dca.ufcg.edu.br〉. Acesso: abril de 2013.

DEMILLO. R. Como funciona o clima. 1 ed. São Paulo: Quark Books, 1998. 226 p.

EMBRAPA-Empresa Brasileira de Pesquisa Agropecuária. Sistema brasileiro de classificação de solos. 4. ed. Brasília: EMBRAPA, 2014. 374 p. 
GALEGO, L. A climatologia tradicional e dinâmica. Boletim Geográfico, Ano 29, n. 215. Rio de Janeiro: 1970.

LIMA, I. F. Fundamentos geográficos do meio físico do Estado de Alagoas. Maceió: Série Estudo de Regionalização, v. 3, Maceió, 1977. 93 p.

LOPES, J. F. B. et al. Deposição e decomposição de serapilheira em área da Caatinga. Revista Agroambiente On-line, v. 3, n. 2. Boa Vista: 2009.

MARENGO, J. A. et al. Variabilidade e mudanças climáticas no semiárido brasileiro. IN: MEDEIROS, S. de S. et al. Recursos hídricos em regiões áridas e semiáridas. 1. ed. Campina Grande: INSA, 2011. p. 383-422.

MONTEIRO, C. A. de F. O estudo geográfico do clima. 1. ed. Florianópolis: Imprensa Universitária, 1999. 68 p. - (Coleção Cadernos Geográficos).

MOLION, L. C. B. Desmatamento e inundações. Ciência Ilustrada, Ano II, n. 15.1983.

NIMER, E. Ensaio de um novo método de classificação climática: contribuição à climatologia intertropical e subtropical, especialmente do Brasil. Boletim Geográfico. Ano 31, n. 227. Rio de Janeiro: 1972.

PEREIRA, E. R. R. et al. Variabilidade do número de dias de chuva no estado de Alagoas. Revista Brasileira de Tecnologia Aplicada nas Ciências Agrárias, v. 5, n. 1. Guarapuava: 2012.

SAMPAIO, E. V. S. B. Overview of the Brazilian Caatinga. In: BULLOCK, S. H.; MOONEY, H. A.; MEDINA, E. Seasonally dry tropical forests. Cambridge: Cambridge University Press, 1995. p. 35-63.

SANTANA, J. A. da S.; SOUTO, J. S. Diversidade e estrutura fitossociológica da caatinga na Estação Ecológica do Seridó-RN, Revista de Biologia e Ciências da Terra, v. 6, n. 2. Campina Grande: 2006.

SEPLANDE. Secretaria de Estado do Planejamento e do Desenvolvimento Econômico. Perfil Municipal. 1. ed. Maceió: SEPLANDE/AL, 2013. 27 p.

SPECIAN, V.; ANDRADE, L. A. de. Implantação de rede de coleta de dados climáticos como subsídio à pesquisa geoambiental no município de Iporá-GO - 1 FASE. 2011. p. 1-6. Sistema de Meteorologia e Hidrologia do Estado de Goiás. Disponível em http://www.simehgo.sectec.go.gov.br/publicacoes/index.php. Acesso em 29 de julho de 2015.

SUPERINTENDÊNCIA DO DESENVOLVIMENTO DO NORDESTE - SUDENE. Normais climatológicas da área da SUDENE. Recife: Serviço de Meteorologia do Ministério da Agricultura, SUDENE, 1963.

Recebido em: 21/11/2016

Aceito para publicação em: 10/01/2017 